\title{
ON THE PERFORMANCE OF AN E-BEAM PUMPED KrF LASER
}

\author{
W.J. WITTEMAN and G.L. OOMEN \\ Department of Applied Physics, Twente University of Technology, \\ Enschede, The Netherlands
}

Received 13 December 1979

\begin{abstract}
The present paper deals with a model for obtaining the optimum performance conditions for the $\mathrm{KrF}_{\mathrm{r}}$ laser. The model is based on the dominant formation, quenching and absorption processes. For a given excitation density the analy sis predicts the maximum photon density rate that can be extracted from the cavity together with the corresponding optimum argon and krypton densities as a function of the excitation rate and outcoupling. The results of various experimental studies indicated in the paper are in good agreement with these predictions. The analysis shows that the maximum efficiency that corresponds with the maximum output defined as the ratio of output power and the ionization energy delivered to argon is about $8 \%$.
\end{abstract}

\section{Introduction}

The $\mathrm{KrF}$ gas-laser [1-4] is the most succesful raregas excimer laser that has demonstrated high specific output powers and high efficiency. Especially by direct e-beam pumping high performance operation has been achieved for different excitation intensities and gas densities. In general one uses for the e-beam pumping the argon-krypton-fluorine mixture. However, from the different results one may conclude that maximum performance depends at least on the excitation intensity regime.

The energy transfer and formation processes in the kinetic chain of this laser have been studied intensively during the last years. A great deal of information on the most important processes has been published [5-15] and the data obtained by various authors are in good agreement with each other. One may conclude from the literature that the dominant formation, quenching and radiation absorption processes are well understood. The basic processes being known, the question arises how the maximum performance condition can be described, such as energy extraction, excitation energy and densities of the gas composition.

In the present paper we shall construct a model that is based on the most relevant processes occurring in the e-beam discharge. Formation, quenching and absorption processes that according to quantitative estimates are roughly less than 10 percent of those used in the model have been neglected. This is not only done for simplicity, but also by the fact that the used rate constants have mostly an inaccuracy of at least 10 percent. From the described model we deduce optimum performance conditions. Then the predictions obtained in this way are compared with experiments.

\section{Kinetic reactions}

The usual gas mixtures for high output energies are at multi-atmosphere pressures and contain more than 95 percent argon, a few percent krypton and only a few tenths of a percent fluorine. The main kinetic chain of the most important processes in such a mixture leading to laser action is given schematically in fig. 1.

In the following we consider a spatial homogeneous excitation mechanism in a homogeneous gas mixture. Further we assume for the interacting radiation field that the intensity $I$, being the sum of the intensities of the two waves running respectively to the left and right, is more or less constant, so that the densities of species and radiation are independent of spatial . coordinates. Further we assume a gas pressure region 


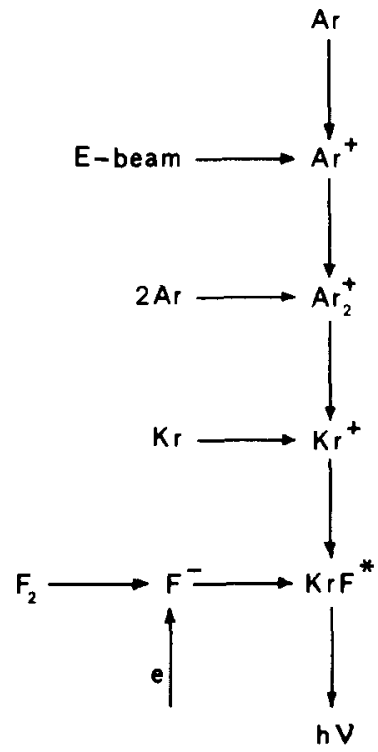

Fig. 1. The main kinetic chain in the laser process.

well above one atmosphere for which the produced argon ions will not primarily recombine with the neg. ative fluorine ions, but will mainly form molecular argon ions in the three-body collisions.

The interaction of the high-energy electrons of the e-beam with the mixture will mainly lead to the production of argon ions with density $\left[\mathrm{Ar}^{+}\right]$because the densities of the other components are much less. The argon ions in turn will mainly produce in three-body collisions with neutral argon molecular argon ions with density $\left[\mathrm{Ar}_{2}^{+}\right]$. The e-beam enenergy transfer to argon is proportional to the argon density, $[\mathrm{Ar}]$, so that this production rate of the argon ion density can be written as $P[\mathrm{Ar}]$, where $P$, depending on current density and energy, is the average ionization rate of an argon atom. Further, there is some production of $\mathrm{Ar}^{+}$by the radiation-absorption process of $\mathrm{Ar}_{2}^{+}$. For the argon ions we have the following rate equation:

$$
\mathrm{d}\left[\mathrm{Ar}^{+}\right] / \mathrm{d} t=P[\mathrm{Ar}]-k_{1}\left[\mathrm{Ar}^{+}\right][\mathrm{Ar}]^{2}+\sigma_{\mathrm{a}} I\left[\mathrm{Ar}_{2}^{+}\right],
$$

where $k_{1}$ is the formation constant of molecular argon ions and $\sigma_{\mathrm{a}}$ the absorption cross-section. The main process suffered by the molecular argon ions are the ionization of krypton (density [ $\mathrm{Kr}]$ ) and the photoabsorption by the intracavity radiation field. The rate equation for the molecular argon ions is then given by:

$$
\begin{aligned}
\mathrm{d}\left[\mathrm{Ar}_{2}^{+}\right] / \mathrm{d} t=k_{1}\left[\mathrm{Ar}^{+}\right][\mathrm{Ar}]^{2}-k_{2}\left[\mathrm{Ar}_{2}^{+}\right][\mathrm{Kr}] \\
-\sigma_{\mathrm{a}} I\left[\mathrm{Ar}_{2}^{+}\right],
\end{aligned}
$$

where $k_{2}$ is the formation constant for krypton ions.

The formation of negative fluorine ions with density $\left[\mathrm{F}^{-}\right]$is mainly due to the dissociative attachment of $\left[\mathrm{F}_{2}\right]$ by secondary electrons formed in the ionization process. The production rate of this ion is proportional to the fluorine density. Although fluorine at its usual pressure of a few torr has some radiation absorption, it turns out that the associated radiation loss is much smaller than what results from the quenching processes. In fact, we calculated that for the usual range of outcoupling in high-power systems $(-\ln R / 2 L>$ $10^{-2}$ ) the effect of fluorine absorption on the output is about $5 \%$. Only at low outcoupling and much higher fluorine density than usual this loss effect becomes considerable. The partial pressure of fluorine is chosen sufficiently high, so that it has no limiting effect on the radiation production. Experimentally we observed that for low fluorine pressures the laser output in. creases more or less linearly with the fluorine density, whereas above a certain (saturating) pressure the output remains more or less constant for increasing fluorine pressure. Only at much higher pressures ( $>6$ torr) some deterioration due to absorption and quenching occurs.

The rate equation for krypton ions with density $\left[\mathrm{Kr}^{+}\right]$contains apart from the production term the strong coulomb interaction with the negative fluorine ions resulting to the lasing molecules. Although there is some direct ionization of krypton by the e-beam, this excitation can be neglected because the relative krypton density in an optimized system is less than $5 \%$. The rate equation for krypton ions will then be given by

$\mathrm{d}\left[\mathrm{Kr}^{+}\right] / \mathrm{d} t=k_{2}\left[\mathrm{Ar}_{2}^{+}\right][\mathrm{Kr}]-k_{3}\left[\mathrm{Kr}^{+}\right]\left[\mathrm{F}^{-}\right]$.

For the inversion mechanism we are, apart from the production term, dealing with stimulated and spontaneous emission and considerable quenching losses. Because the usual systems have high outcoupling per unit of length, which means for the laser process high inversion densities, the quenching losses are most serious. Although many species in the system will quench the lasing molecules, the dominant processes are two- and three-body collisions with argon, the 
Table 1

Dominant formation rate constants

\begin{tabular}{lll}
\hline reactions & rate constants & ref. \\
\hline $\mathrm{Ar}^{+}+2 \mathrm{Ar} \rightarrow \mathrm{Ar}_{2}^{+}$ & $k_{1}=2.5 \times 10^{-31} \mathrm{~cm}^{6} \mathrm{~s}^{-1}$ & {$[10]$} \\
$\mathrm{Ar}_{2}^{+}+\mathrm{Kr} \rightarrow \mathrm{Kr}^{+}$ & $k_{2}=7.5 \times 10^{-10} \mathrm{~cm}^{3} \mathrm{~s}^{-1}$ & {$[11]$} \\
$\mathrm{Kr}^{+}+\mathrm{F}^{-} \rightarrow \mathrm{KrF}^{*}$ & $k_{3}=3 \times 10^{-6} \mathrm{~cm}^{3} \mathrm{~s}^{-1}$ & {$[12]$} \\
\hline
\end{tabular}

three-body collisions with argon and krypton and the two-body collisions with fluorine. We have for the inversion with density $\left[\mathrm{KrF}^{*}\right]$ :

$$
\begin{aligned}
& \mathrm{d}\left[\mathrm{KrF}^{*}\right] / \mathrm{d} t=k_{3}\left[\mathrm{Kr}^{+}\right]\left[\mathrm{F}^{-}\right]-\sigma_{\mathrm{st}} I\left[\mathrm{KrF}^{*}\right]-(1 / \tau)\left[\mathrm{KrF}^{*}\right] \\
& -k_{4}[\mathrm{Ar}]\left[\mathrm{KrF}^{*}\right]-k_{5}[\mathrm{Ar}]^{2}\left[\mathrm{KrF}^{*}\right] \\
& -k_{6}[\mathrm{Kr}][\mathrm{Ar}]\left[\mathrm{KrF}^{*}\right]-k_{7}\left[\mathrm{~F}_{2}\right]\left[\mathrm{KrF}^{*}\right]
\end{aligned}
$$

where $\sigma_{\mathrm{st}}$ is the stimulated emission cross-section, $\tau$ is the spontaneous lifetime, and $k_{4}, k_{5}, k_{6}$, and $k_{7}$ are the respective quenching rates.

The radiation field within the cavity is mainly subjected to stimulated emission, outcoupling, and absorption by molecular argon ions, fluorine and fluorine ions. We have the following equations for the photondensity flux:

$(1 / c) \mathrm{d} I / \mathrm{d} t=\sigma_{\mathrm{st}} I\left[\mathrm{KrF}^{*}\right]-\gamma I-\sigma_{\mathrm{a}} I\left[\mathrm{Ar}_{2}^{+}\right]$,

where

$\gamma=\gamma_{0}+\gamma_{\mathrm{a}}$

$\gamma_{0}=-\ln R / 2 L$ is the outcoupling factor. $R$ and $L$ are respectively the product of mirror reflectivities and mirror separation distance,

$\gamma_{\mathrm{a}}=\sigma_{\mathrm{F}^{-}}\left[\mathrm{F}^{-}\right]+\sigma_{\mathrm{F}_{2}}\left[\mathrm{~F}_{2}\right]$,

being the absorption loss by the fluorine ions and molecules. This loss is, especially at low excitation densities and argon pressure of about $2 \mathrm{~atm}$ or less, much

Table 2 .

Dominant rate constant for quenching $\mathrm{Kr}_{\mathbf{r}} \mathrm{F}^{*}$

\begin{tabular}{lll}
\hline quencher & rate constants & ref. \\
\hline $\mathrm{Ar}$ & $k_{4}=1.8 \times 10^{-12} \mathrm{~cm}^{3} \mathrm{~s}^{-1}$ & {$[5,6]$} \\
$2 \mathrm{Ar}$ & $k_{5}=1.1 \times 10^{-31} \mathrm{~cm}^{6} \mathrm{~s}^{-1}$ & {$[5,6]$} \\
$\mathrm{Ar}+\mathrm{Kr}$ & $k_{6}=6.5 \times 10^{-31} \mathrm{~cm}^{6} \mathrm{~s}^{-1}$ & {$[7,12]$} \\
$\mathrm{F}_{2}$ & $k_{7}=5.2 \times 10^{-10} \mathrm{~cm}^{3} \mathrm{~s}^{-1}$ & {$[6,8,7,15]$} \\
\hline
\end{tabular}

Table 3

Dominant radiation interaction

\begin{tabular}{lll}
\hline species & cross-section & ref. \\
\hline $\mathrm{Ar}_{2}^{+}$ & $\sigma_{\mathrm{a}}=1.5 \times 10^{-17} \mathrm{~cm}^{2}$ & {$[9]$} \\
$\mathrm{KrF}^{*}$ & $\sigma_{\mathrm{st}}=1.8 \times 10^{-16} \mathrm{~cm}^{2}$ & {$[14]$} \\
$\mathrm{KrF}^{*}$ & $\tau=9 \times 10^{-9} \mathrm{~s}$ & {$[13,14,15]$} \\
$\mathrm{F}_{2}$ & $\sigma_{\mathrm{F}_{2}}=1.5 \times 10^{-20} \mathrm{~cm}^{2}$ & {$[9]$} \\
$\mathrm{F}^{-}$ & $\sigma_{\mathrm{F}}^{-}=5.6 \times 10^{-18} \mathrm{~cm}^{2}$ & {$[9]$} \\
\hline
\end{tabular}

smaller than the outcoupling loss of a quartz flat. Due to the large cross-section of the secondary electrons for the dissociative attachment their lifetime is only a few nanoseconds. Therefore we assume that the $\mathrm{F}^{-}$ density is about equal to the sum of all positive ion densities.

The numerical values of the quenching and formation rates and radiation-interaction constants used in eqs. (1) to (7) are listed in tables 1, 2, and 3.

For the laser parameters used in the range of maximum operation performance it is found that the time constants for the species and output power following the excitation pulse is in the order of a few nanoseconds. This is found by a numerical evaluation of the above equations, but also from experiments. In fact we observed that the radiation pulse follows rather accurately the shape of the excitation pulse (fig. 2). This means that for an excitation process during a time larger than those time constants the laser process can be considered quasi-stationary. Therefore we study the steady-state solution of the equations (1) to (5). We find:

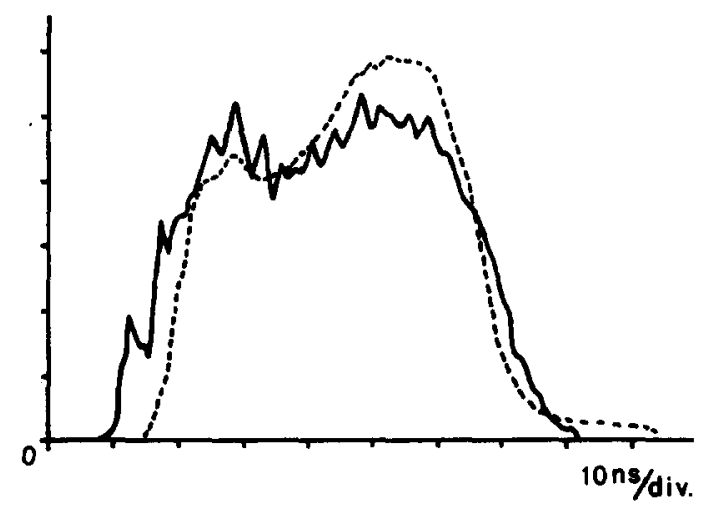

Fig. 2. The time behaviour of a current pulse of about $50 \mathrm{~ns}$ and the corresponding laser output pulse. 
$W=P[\mathrm{Ar}]-\frac{W \sigma_{\mathrm{a}} P[\mathrm{Ar}]}{\gamma k_{2}[\mathrm{Kr}]}-\left(\frac{\gamma}{\sigma_{\mathrm{st}}}+\frac{\sigma_{\mathrm{a}}}{\sigma_{\mathrm{st}}} \frac{P[\mathrm{Ar}]}{k_{2}[\mathrm{Kr}]}\right) Q$,

where $W=\gamma I$ is the production rate of photons per unit volume:

$Q=k_{4}[\mathrm{Ar}]+k_{5}[\mathrm{Ar}]^{2}+k_{6}[\mathrm{Kr}][\mathrm{Ar}]+k_{7}\left[\mathrm{~F}_{2}\right]+1 / \tau$.

The negative fluorine density is obtained by calculating the steady-state values of $\left[\mathrm{Ar}^{+}\right],\left[\mathrm{Ar}_{2}^{+}\right]$, and $\left[\mathrm{Kr}^{+}\right]$. The value of $\left[\mathrm{Kr}^{+}\right]$is described by

$$
\begin{aligned}
& {\left[\mathrm{Kr}^{+}\right]^{2}+\left[\mathrm{Kr}^{+}\right]\left(\frac{P}{k_{1}[\mathrm{Ar}]}\right.} \\
& \left.+\frac{P \sigma_{\mathrm{a}} I}{k_{1} k_{2}[\mathrm{Kr}][\mathrm{Ar}]}+\frac{P[\mathrm{Ar}]}{k_{2}[\mathrm{Kr}]}\right)=\frac{P[\mathrm{Ar}]}{k_{3}} .
\end{aligned}
$$

\section{Experimental comparison with model}

In order to verify the usefulness of the predicted model we studied the laser performance of an e-beam excited medium by means of a planar diode of $50 \times 5$ $\mathrm{cm}^{2}$ coupled to a marx generator and waterline $(50 \mathrm{~ns})$ capable of injecting electrons with a current up to $90 \mathrm{~A} / \mathrm{cm}^{2}$ at $600 \mathrm{keV}$.

The power dissipation in the laser volume is found by means of the Berger-Seltzer tables for argon and by applying a correction factor of 2.3 for the nonrectilinear electron paths. By using the energy loss per argon ion pair $(26 \mathrm{eV})$ and the particle density the ionization rate per atom is calculated. In table 4 we list the current density, power dissipation per unit volume and unit atmosphere, and ionization rate per argon atom.

The cavity is formed by a plane $\mathrm{Al}$ mirror and a

Table 4

\begin{tabular}{|c|c|c|}
\hline $\begin{array}{l}\text { current } \\
\text { density } \\
{\left[\mathrm{A} / \mathrm{cm}^{2}\right]}\end{array}$ & 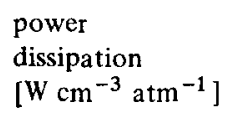 & $\begin{array}{l}\text { ionization } \\
\text { rate } \\
{\left[\mathrm{s}^{-1} \text { atom }^{-1}\right]}\end{array}$ \\
\hline 62 & $0.36 \times 10^{6}$ & $3.5 \times 10^{3}$ \\
\hline 71 & $0.41 \times 10^{6}$ & $4 \times 10^{3}$ \\
\hline 76 & $0.44 \times 10^{6}$ & $4.3 \times 10^{3}$ \\
\hline 90 & $0.51 \times 10^{6}$ & $5 \times 10^{3}$ \\
\hline
\end{tabular}

Experimental parameters

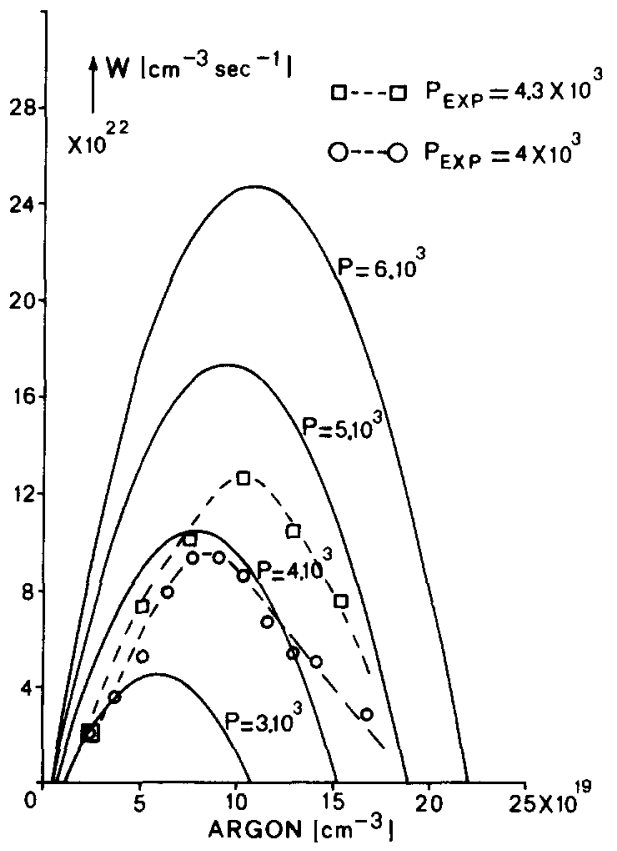

Fig. 3. The measured and calculated extracted photon density rate as a function of the argon density for krypton and fluor densities of respectively $3 \times 10^{18}$ and $6 \times 10^{16} \mathrm{~cm}^{-3}$.

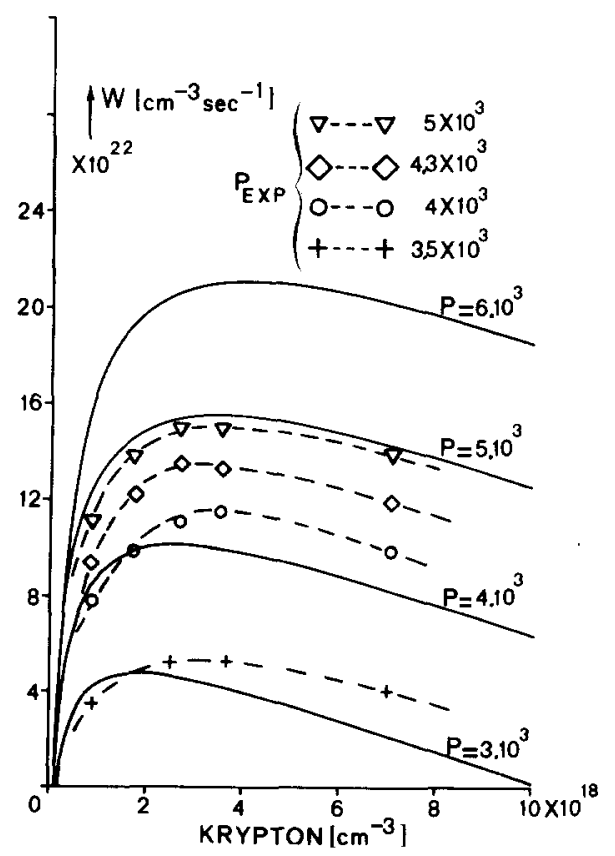

Fig. 4. The measured and calculated ex tracted photon density rate as a function of the krypton density for argon and krypton densities of respectively $6.5 \times 10^{19}$ and $6 \times 10^{16} \mathrm{~cm}^{-3}$. 
plane-parallel quartz plate for outcoupling. The output coupling factor is estimated as $\gamma_{0}=3 \times 10^{-2} \mathrm{~cm}^{-1}$.

In fig. 3 we have plotted both the calculated photon density rate $W$ according to eq. (8) and the measured rates as a function of the argon density for different values of the ionization rate $P$ of the argon atoms. The krypton and fluorine densities were kept constant respectively $3 \times 10^{18}$ and $6 \times 10^{16} \mathrm{~cm}^{-3}$.

In fig. 4 we have plotted for the same loss factor the calculated and measured photon density rate $W$ as a function of krypton for various ionization rates. The argon and fluorine density were kept constant respectively $6.5 \times 10^{19}$ and $6 \times 10^{16} \mathrm{~cm}^{-3}$. The experimental data plotted in both figures were obtained after first passivating the system.

\section{Maximum performance}

For obtaining the optimum performance conditions of the laser system it is advantageous to substitute in eq. (8) $\bar{W}=W / P$ and $\bar{\gamma}=\gamma / P$. Then we obtain
$\bar{W}\left(1+\frac{\sigma_{\mathrm{a}}[\mathrm{Ar}]}{\bar{\gamma} k_{2}[\mathrm{Kr}]}\right)=[\mathrm{Ar}]-\left(\frac{\bar{\gamma}}{\sigma_{\mathrm{st}}}+\frac{\sigma_{\mathrm{a}}}{\sigma_{\mathrm{st}}} \frac{[\mathrm{Ar}]}{k_{2}[\mathrm{Kr}]}\right) Q$.

For a given value of $\bar{\gamma}$ the maximum of $\bar{W}$ and the corresponding values of $[\mathrm{Ar}]$ and $[\mathrm{Kr}]$ can be calculated from eq. (11). This maximum, indicated by $W_{\mathrm{m}} / P$, is plotted in fig. 5 as a function of $\bar{\gamma}$. Also the densities of argon and krypton for which this maximum is reached are plotted.

We define the efficiency of the laser process as $\eta=$ $W / P[\mathrm{Ar}]$, being the ratio of the photon density rate and the excitation rate density. In fig. 5 we have also plotted the values of $\eta$ for maximum output as a function of $\bar{\gamma}$. It is seen that the efficiency at optimum performance varies only slowly and that a broad maximum is obtained for $\gamma=0.3 \times 10^{-5} \mathrm{~cm}^{-1} \mathrm{~s}$. It should be noted that for a given current density higher efficiencies can be reached for systems that are not optimized.

The results of fig. 5 have been compared with experimental results. In table 5 we have listed two experiments with maximum output power and the cor-

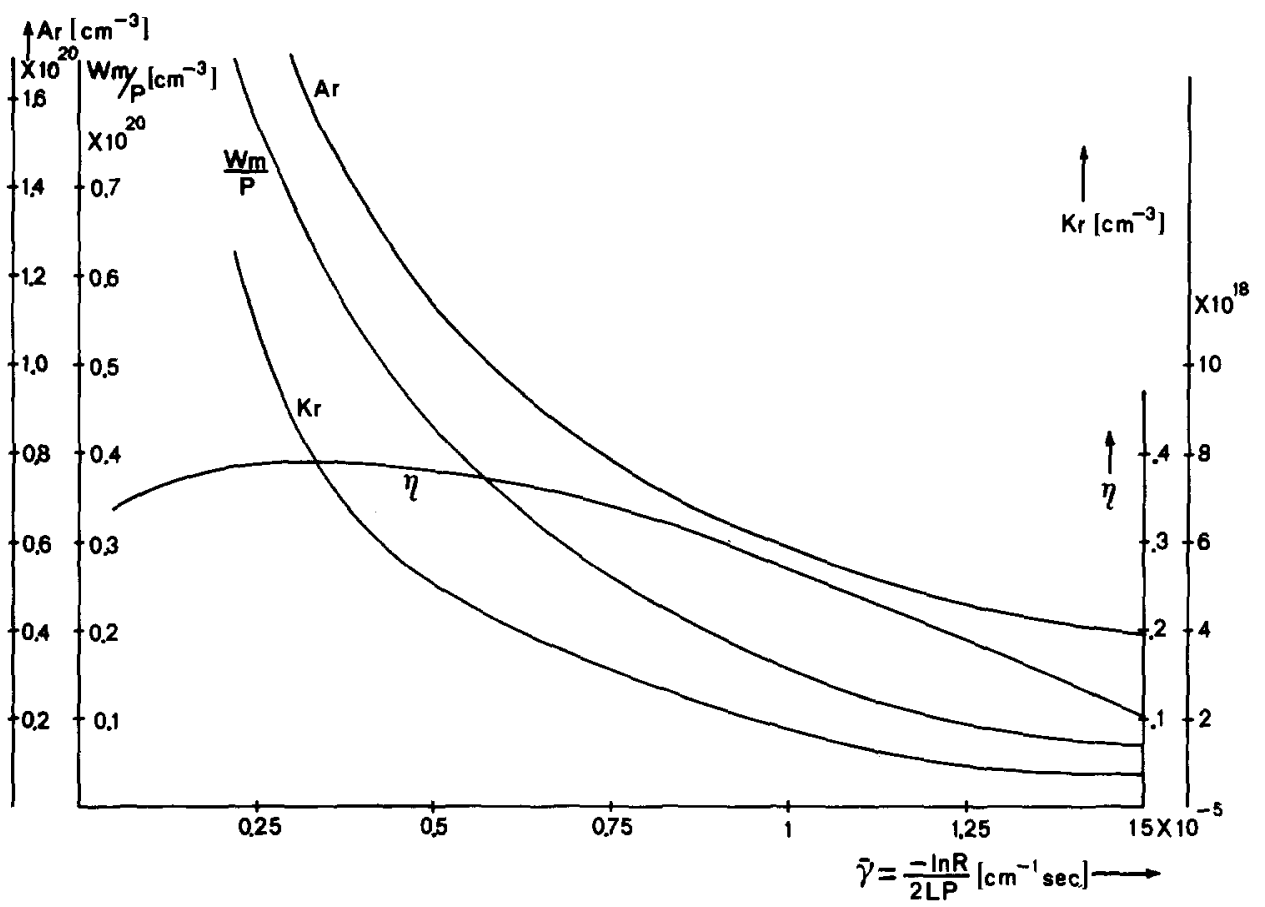

Fig. 5. The ratio of maximum extracted photon density to the average excitation rate. The argon and krypton densities for which the maximum power is reached are also plotted. Further, the efficiency $\eta$ that corresponds with the maximum power is also indicated. 
Table 5

Performance conditions

\begin{tabular}{|c|c|c|c|c|c|c|c|c|}
\hline $\begin{array}{l}i \\
\mathrm{~A} / \mathrm{cm}^{2}\end{array}$ & $\begin{array}{l}P \\
\mathrm{~s}^{-1}\end{array}$ & $\begin{array}{l}\bar{\gamma} \\
\mathrm{cm} \mathrm{s}\end{array}$ & $\begin{array}{l}\mathrm{Ar} \\
\exp \end{array}$ & $\begin{array}{l}\text { Ar } \\
\text { theor }\end{array}$ & $\begin{array}{l}\mathrm{Kr} \\
\exp \end{array}$ & $\begin{array}{l}\mathrm{Kr} \\
\text { theor }\end{array}$ & $\begin{array}{l}W_{\mathrm{m}} \\
\exp \end{array}$ & $\begin{array}{l}W_{\mathrm{m}} \\
\text { theor }\end{array}$ \\
\hline 178 & $1 \times 10^{4}$ & $0.4 \times 10^{-5}$ & $11 \times 10^{19}$ & $13.5 \times 10^{19}$ & $6.2 \times 10^{18}$ & $7 \times 10^{18}$ & $5.7 \times 10^{23}$ & $5.3 \times 10^{23}$ \\
\hline 71 & $4 \times 10^{3}$ & $0.85 \times 10^{-5}$ & $6.7 \times 10^{19}$ & $7 \times 10^{19}$ & $3 \times 10^{18}$ & $2.6 \times 10^{18}$ & $1 \times 10^{23}$ & $0.9 \times 10^{23}$ \\
\hline
\end{tabular}

responding optimum gas densities under various excitation and outcoupling conditions. The photon density flux coupled out and the gas densities are compared with the calculated values. The experimental photon density production in the cavity is obtained from the observed photon density flux by multiplying its value by $1+\gamma_{\mathrm{a}} / \gamma_{0}$ because of the absorption by $\mathrm{F}^{-}$and $\mathrm{F}_{2}$. In the first row we list the experimental parameters of our coaxial device [16] with a current density of about $178 \mathrm{~A} / \mathrm{cm}^{2}$ and $\gamma_{\mathrm{a}}=1 \times 10^{-2}$. The second row is related to our above mentioned experiments with the planar diode and $\gamma_{\mathrm{a}}=0.4 \times 10^{-2}$. The excitation length $(50 \mathrm{~cm})$ and the pulse duration $(50 \mathrm{~ns})$ are for both systems the same.

\section{Discussion}

The model discussed in the present paper predicts rather well the performance as a function of gas pressures, excitation rate, and outcoupling. It is seen from fig. 3 and 4 that the maximum output is much more sensitive to a fractional change of argon than to the same fractional change of krypton. In fact we found both experimentally and theoretically that increasing krypton density above its optimum has only little effect on the output. Further we found that in order to extract the highest power we have to keep the optical cavity output coupling as low as possible as long as the radiation absorption processes are low. The smaller the outcoupling, the smaller is the inversion density and consequently the smaller are the quenching losses. For lower quenching rates the argon pressure can be increased so that higher input energies are obtained. This process is also balanced by the higher intracavity radiation absorption with the molecular argon ions.

The analysis shows that the maximum fraction of initial argon ions that corresponds with the output photons, given by $\eta$, has a maximum of about $40 \%$. The quantum efficiency equal to the ratio of photon energy and argon ionization energy is 0.2 . Thus the maximum efficiency at the optimized output power is about $8 \%$. Systems that are not optimized with respect to output power may yield higher efficiences at lower output powers.

\section{References}

[1] G.C. Tisone, A.K. Hays and J.M. Hoffman, Optics Comm. 15 (1975) 188.

[2] M.L. Bhaumik, R.S. Bradford Jr, and E.R. Ault, Appl. Phys. Lett. 28 (1976) 23.

[3] J.M. Hoffman, A.K. Hays and G.C. Tisone, Appl. Phys. Lett. 28 (1976) 538.

[4] G.C. Tisone, E.L. Patterson and J.K. Rice, Appl. Phys. Lett. 35 (1979) 437.

[5] J.G. Eden, W.R. Waynant, S.K. Searles and R. Burnham, J. Appl. Phys. 49 (1978) 5368.

[6] J.G. Eden, W.R. Waynant, S.K. Searles and R. Burnham, Appl. Phys. Lett. 32 (1978) 733.

[7] M. Rokin, J.H. Jacob and J.A. Mangano, Phys. Rev. A16 (1977) 2216.

[8] G.P. Quigley and W.M. Hughes, Appl. Phys. Lett. 32 (1978) 627.

[9] W.B. Lacina and D.B. Cohn, Appl. Phys. Lett. 32 (1978) 106.

[10] E.W. McDaniel, V. Ermak, A. Dalgarno, E.E. Ferguson and L. Friedman, Ion-molecule reactions (WileyInterscience, New York, 1970) p. 338.

[11] D.K. Bohme, N.G. Adams, M. Moselman, D.B. Dunkin and E.E. Ferguson, J. Chem. Phys. 52 (1970) 5094.

[12] J.A. Mangano, J.H. Jacob, M. Rokin and A. Hawryluk, Appl. Phys. Lett. 31 (1977) 26.

[13] R. Burnham and S.K. Searles, J. Chem. Phys. 67 (1977) 5967.

[14] J. Tellinghuisen, A.K. Hays, J.M. Hoffman and G.C. Tisone, J. Chem. Phys. 65 (1976) 4473.

[15] G.P. Quigley and W.M. Hughes, Appl. Phys. Lett. 32 (1978) 627.

[16] G.L. Oomen and W.J. Witteman, Optics Comm. 32 (1980) 461. 